\title{
Pesticide Toxicology
}

National Cancer Institute

\section{Source}

National Cancer Institute. Pesticide Toxicology. NCl Thesaurus. Code C18934.

The toxicology of pesticides 